\title{
Genetic data support reproductively isolated species in the endemic Cladophoraceae (Chlorophyta) of Lake Baikal, Russia
}

\author{
Sergio Díaz Martínez (1) ${ }^{1,2}$, Christian Boedeker (1) ${ }^{1}$, and Giuseppe C. Zuccarello (i) ${ }^{1}$ \\ ${ }^{1}$ School of Biological Sciences, Victoria University of Wellington, PO Box 600, Wellington 6140, New Zealand \\ ${ }^{2}$ Herbario FEZA, Facultad de Estudios Superiores Zaragoza, UNAM, Batalla de 5 de mayo S/N Col. Ejército de Oriente, Ciudad de México C.P. 09230, \\ Mexico
}

\begin{abstract}
Ancient lakes are centres of biological diversification that hold many examples of adaptive radiation and species flocks. The recently discovered species flock of Cladophoraceae in Lake Baikal is a group of green algae that exhibit low genetic divergence in ribosomal markers (LSU, SSU, and ITS), but wide morphological differentiation. Microsatellite markers showed evidence of polyploidy in this group, requiring alternate data scoring methodologies. In this study, we use two clustering methods (STRUCTURE and Gaussian Clustering) to delineate species within 15 distinct morphotaxa of the cladophoralean Baikal clade. The two cluster analyses produced comparable results, although subtle differences in the assignment of individuals were observed. Our results indicate that many morphologically distinguishable species are discrete genetic clusters supporting reproductive isolation. This is the case for Chaetomorpha (= Ch.) baicalensis, the attached form of Ch. curta, Ch. moniliformis, Cladophora $(=C l$.) compacta, and $\mathrm{Cl}$. kursanovii. The unattached form of $\mathrm{Ch}$. curta and a species of Rhizoclonium are recovered as growth forms of $\mathrm{Ch}$. moniliformis and the attached form of Ch. curta, respectively. The remaining morphotaxa were not clearly delimited. While we have evidence for polyploidy within this species flock, it was not possible to determine the ploidy level of each individual with accuracy as no correlation in the number of alleles was observed between loci. A more detailed study including other sources of data, such as nuclear DNA content or chromosome counts, is required to demonstrate the ploidy changes and their role in speciation in these species.
\end{abstract}

ARTICLE HISTORY

Received 13 February 2020

Accepted 26 May 2020

Published online 02 July

2020

\section{KEYWORDS}

Morphotaxa; Population genetics; Speciation; Species flock; SSR

\section{INTRODUCTION}

Ancient lakes, lakes older than 1 million years (mya), are well known centres of biological diversification that contain some of the most remarkable examples of endemism, speciation, species flocks, and adaptive radiations (Cristescu et al. 2010; Wilke et al. 2008). Lake Baikal, located in south-eastern Siberia, Russia, is the oldest lake in the world (about 30 mya; Mats 1993). Like other ancient lakes, it is considered an evolutionary laboratory due to its unique biological diversity. The fauna contains approximately 2600 species, more than half are endemic, and many taxonomic groups are considered the products of adaptive radiations (Barluenga et al. 2006; Fitzpatrick et al. 2009; Herder et al. 2008; Keller et al. 2013; Salzburger \& Meyer 2004; Seehausen 2006; Sherbakov 1999; Wilke et al. 2008). However, the filamentous green algae of the lake have not been extensively studied (for examples, see Boedeker et al. 2018; Volkova et al. 2018). The species flock of Baikalian Cladophoraceae (Ulvophyceae, Chlorophyta) is a group of freshwater green algae that includes taxa endemic to Lake Baikal. The taxonomy of the species in this group was based mainly on morphology and recognised 16 distinct taxa (4 genera, 14 species, and 2 varieties; Boedeker et al. 2018; Izhboldina 2007) with a morphological range as broad as the entire family Cladophoraceae, which includes filamentous genera such as the branched Cladophora Kützing and the unbranched Chaetomorpha Kützing and Rhizoclonium Kützing (Boedeker et al. 2016). Species within Cladophoraceae usually have a haplodiplontic and isomorphic life cycle (Škaloud et al. 2018). The actual reproduction mode of Baikalian species is unknown, but at least some asexual reproduction is likely, as it has been observed in the common freshwater Cladophora glomerata (Linnaeus) Kützing (van den Hoek et al. 1995; Zulkifly et al. 2013).

Recent studies using nuclear ribosomal markers (SSU, LSU, and ITS) have revealed that the mostly endemic Baikalian Cladophoraceae are a monophyletic group ('Baikal clade') with low levels of genetic differentiation, nested within the genetically diverse genus Rhizoclonium (Boedeker et al. 2018). This was a striking result, considering the group's morphological diversity. Phylogenetic analyses of ribosomal markers resolved the Baikal clade into two major groups (A and B; Fig. S1; Boedeker et al. 2018) but were not able to support most of the morphotaxa.

The low genetic differentiation based on rDNA markers, the wide morphological differentiation between the taxa, and the cooccurrence of many taxa in the same localities across the lake suggest that this group could be a species flock that has undergone sympatric speciation (Boedeker et al. 2018). In addition, the recent development and use of simple sequence repeat (SSR) markers indicates that polyploidy is likely in these taxa (Díaz- 
Martínez et al. 2020). Therefore, the clade of Baikalian Cladophoraceae is an interesting group for studying speciation in green algae. However, a better understanding of the species limits is required to determine the underlying evolutionary processes (i.e. possible sympatric speciation).

Species delimitation is crucial for many aspects of biology. Although there is still debate about the definition of species and how they should be delimited, there is general agreement that species are independently evolving metapopulation lineages (De Queiroz 2007; Wiens 2007). This allows for a set of operational criteria to support and delimit species, such as reproductive isolation, phylogenetic patterns, and genetic clustering (De Queiroz 2007). The use of these criteria, combined with new methods, has improved our understanding in recognising species and how to delimit them (Carstens et al. 2013; Hausdorf \& Hennig 2010; Leliaert et al. 2014; Zhang et al. 2013).

Many current phylogenetic species delimitation methods are based on DNA sequence data that are used in barcode gap determination (Puillandre et al. 2012), coalescent-based groupings (Fujisawa \& Barraclough 2013), or tree-based methods (Zhang et al. 2013). These approaches provide a good overview of species diversification and are widely used in taxonomic assessments and diversity exploration (e.g. Díaz-Martínez et al. 2016; Muangmai et al. 2014). Although these methods are useful, they are not free of caveats. Problems can arise when the patterns recovered do not reflect the speciation process, for example due to hybridisation or incomplete lineage sorting, or when the phylogenetic signal of the selected genes is too low due to low mutation rates or recent divergence (Carstens et al. 2013; Edwards \& Knowles 2014).

Delimitation methods based on population genetics, on the other hand, can provide more accurate species delimitation in cases where DNA sequence methods fail (Carstens et al. 2013; Hausdorf \& Hennig 2010; Shaffer \& Thomson 2007). Compared to DNA sequence-based methods based on coalescence (Fujisawa \& Barraclough 2013) or genetic distances (Puillandre et al. 2012), this approach requires more extensive sampling and more markers to capture the genetic diversity of the populations, but can reveal clusters of genetically similar genotypes that have evolved independently with little or no ongoing gene flow (Hausdorf \& Hennig 2010). The resulting clusters could be interpreted as putative species following the Genotypic Cluster Criterion (Mallet 1995), that considers a species as a monotypic or polytypic cluster of biological entities identified by morphology or genetics, and the Intrinsic Reproductive Isolation criterion (Mayr 2000) where reproductively isolated populations accumulate genetic differences over time. However, this method is limited by stage of the speciation process, and populations in early stages of speciation may be difficult to delimitate (Hausdorf \& Hennig 2010). On the other hand, it has been demonstrated that intraspecific genetic variation could lead to an overestimation of species if the genetic clusters are not interpreted carefully (Sukumaran \& Knowles 2017).

The most commonly used methods in population genetics include clustering algorithms using model-free multivariate analysis such as Gaussian clustering or discriminant analysis of principal components (Hausdorf \& Hennig 2010; Jombart et al. 2010), or explicit models like STRUCTURE or Structurama (Huelsenbeck et al. 2011;
Pritchard et al. 2000) using different types of genetic markers, such as single nucleotide polymorphisms (SNPs) and SSRs. SSRs are repetitive short DNA sequences (c. 2-6 base pairs) scattered in the genomes of many organisms. Other markers such as single nucleotide polymorphism have gained popularity due to recent advances in sequencing technology (Defaveri et al. 2013; Nielsen et al. 2011), easy genotyping, and low homoplasy levels (Shaffer \& Thomson 2007). Regardless, some advantages of using SSRs over other markers are their codominance, neutrality, and high levels of polymorphism (Selkoe \& Toonen 2006). In addition, advances in next-generation sequencing make obtaining a large number of potential SSRs rapid and cost effective (Schoebel et al. 2013). Being based on polymerase chain reaction techniques, SSRs are especially useful when biological material is poorly preserved or in small quantities, conditions occurring in the Baikal clade.

In this study, we explored the species boundaries of the species flock of Cladophoraceae of Lake Baikal by genetic clustering analyses for species delimitation using recently developed putatively neutral SSR markers (Díaz-Martínez et al. 2020). We also determined whether the genetic clusters are consistent with the currently recognised morphotaxa sensu Izhboldina (2007) and the results obtained by Boedeker et al. (2018).

\section{MATERIAL AND METHODS}

\section{Taxon sampling}

A total of 727 samples of 15 taxa were analysed (Table S1). The initial identification was done using morphological characters (Boedeker et al. 2018; Izhboldina 2007; see Table S2). In this work we considered each morphotype independently as a preliminary morphotaxon, making a total of 15 distinct units (Table 1).The samples included: two distinct morphotypes of $C h$. curta (attached and unattached form) and two dubious identifications of Cl. globulus/Cl. compacta and Cl. globulus/Cl. pulvinata. Samples of Chaetocladiella pumila (K.I.Meyer) K.I.Meyer

Table 1. Endemic morphotaxa of Cladophoraceae from Lake Baikal analysed in this study. The groups correspond to the two major clades ( $A$ and $B$ ) found in Boedeker et al. (2018; Fig. S1) using rDNA sequences.

\begin{tabular}{lc}
\hline Taxa & Group \\
\hline Chaetomorpha baicalensis K.I.Meyer & $\mathrm{B}$ \\
Chaetomorpha curta (Skabitschevsky) Skabitschevsky, attached form & $\mathrm{A}$ \\
\hline Chaetomorpha curta, unattached form & $\mathrm{A}$ \\
Chaetomorpha moniliformis Skabitschevsky & $\mathrm{A}$ \\
\hline Cladophora compacta (K.I.Meyer) K.I.Meyer & $\mathrm{B}$ \\
\hline Cladophora floccosa K.I.Meyer var. floccosa & $\mathrm{B}$ \\
\hline Cladophora floccosa var. irregularis Skabitschevsky & $\mathrm{B}$ \\
\hline Cladophora globulus (C.Meyer) C.Meyer/Cladophora compacta & $\mathrm{B}$ \\
\hline Cladophora globulus/Cl. pulvinate (K.I.Meyer) K.I.Meyer & $\mathrm{B}$ \\
Cladophora kursanovii Skabitschevsky & $\mathrm{A}$ \\
\hline Cladophora meyeri Skabitschevsky var. meyeri & $\mathrm{B}$ \\
\hline Cladophora meyeri Skabitschevsky var. gracilior (Meyer) Hollerbach & $\mathrm{B}$ \\
\hline Cladophora pulvinata (K.I.Meyer) K.I.Meyer & $\mathrm{B}$ \\
\hline Gemmiphora compacta Skabitschevsky & $\mathrm{B}$ \\
\hline Rhizoclonium sp. Kützing & $\mathrm{A}$ \\
\hline
\end{tabular}




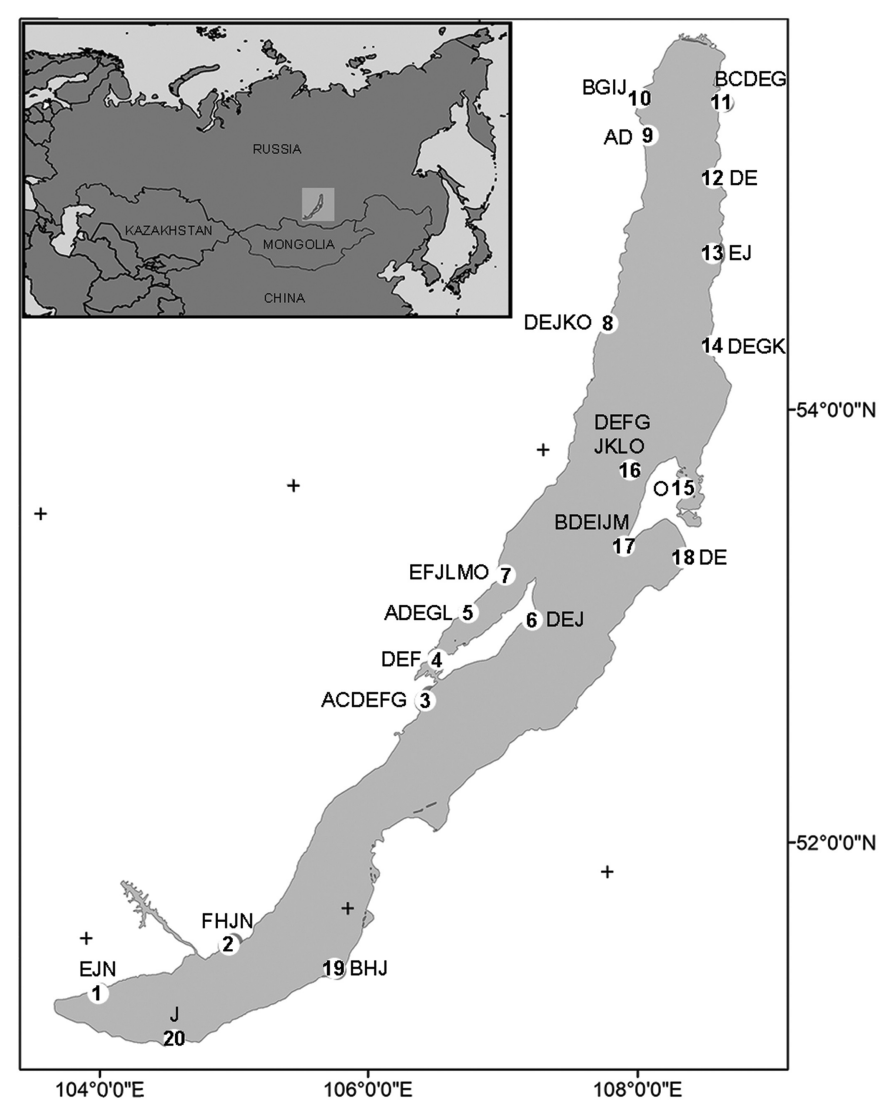

Fig. 1. Map of Lake Baikal indicating the collection localities and morphotaxa found at each location. Morphotaxa: A, Chaetomorpha (= Ch.) baicalensis; B, Ch. curta attached form; C, Ch. curta unattached form; D, Ch. moniliformis; E, Cladophora (= Cl.) compacta; $\mathrm{F}, \mathrm{Cl}$. floccosa var. floccosa; G, Cl. floccosa var. irregularis; $\mathrm{H}, \mathrm{Cl}$. globulus/Cl. Compacta; I, Cl. globulus/Cl. pulvinata; J, Cl. kursa novii; K, Cl. meyeri var. gracilior; L, Cl. meyeri var. meyeri; $\mathrm{M}, \mathrm{Cl}$. pulvinata; N Gemmiphora compacta; O, Rhizoclonium sp. Localities and approximate coordinates in Table S3.

\& Skabitschevsky and Chaetocladiella litoralis (Skabitschevsky) Meyer \& Skabitschevsky were not included because sample amplification failed (Díaz-Martínez et al. submitted). Samples were collected in 20 localities around Lake Baikal during September 2014 by C. Boedeker using scuba diving (Fig. 1; Table S3). A target number of 10 individuals per morphotaxon per locality were collected and dried in silica gel for DNA extractions.

\section{DNA extractions and SSRs amplification}

Total genomic DNA was extracted using the Chelex protocol (Goff \& Moon 1993) to avoid losing material during the extraction. The primers and amplification conditions followed Díaz-Martínez et al. (2020). Eleven SSR markers were used in samples of morphotaxa belonging to clade A, while only nine were used in samples in clade B, similar to previous results (Díaz-Martínez et al. 2020).

PCR products were mixed in 96-well plates, combining up to four different dyes per well, and sent to Macrogen Inc. (Seoul, Korea) for fragment analysis on an ABI3730XL Genetic Analyser (Life Technologies Corporation, Carlsbad, California, USA.) with GeneScan 500 LIZ as a size standard.
Chromatograms were analysed using GeneMarker 2.0.2 (SoftGenetics, LLC, State College, Pennsylvania, USA).

A previous study showed that individuals of the species flock of Cladophoraceae of Lake Baikal are likely polyploid as they showed more than two alleles (signal peaks) per locus per individual (Díaz-Martínez et al. 2020). Common statistics designed for microsatellites such as $\mathrm{F}_{\mathrm{st}}$, expected heterozygosity, or linkage disequilibrium, are based on diploid individuals and cannot be used in polyploids if the allele dosage is uncertain or if the ploidy level is high (Bruvo et al. 2004; Obbard et al. 2006; Pfeiffer et al. 2011; García-Verdugo et al. 2013). To overcome this problem, alleles were coded into a binary presence (1)-absence (0) matrix as 'allele phenotypes', an approach successfully used in population genetics of many taxa (Andreakis et al. 2009; Cidade et al. 2013; LópezVinyallonga et al. 2015; Samah et al. 2016; Sampson \& Byrne 2012). In spite of the reduction of informative power, this approach allows analysis of polyploids and the combination of individuals with different ploidy levels (Andreakis et al. 2009; Bruvo et al. 2004). Other statistics, such as total number of alleles per locus and number of private alleles are not affected (López-Vinyallonga et al. 2015). Loci for which alleles failed to amplify in particular samples were coded as missing data. For loci 15, 515-35, and 515-46 in samples of group $\mathrm{B}$, alleles were coded as true absences as we considered them informative for cluster analysis as they correlate with the morphotaxa.

Summary statistics for each SSR were calculated, including total number of alleles and alleles per individual. The polymorphic information content for dominant markers (PIC), a good measure of genetic diversity (Roldan-Ruiz et al. 2000), was calculated in GDdom (Abuzayed et al. 2017). Statistics for all morphotypes were calculated in GenAlEx 6.5 (Peakall \& Smouse 2012) including the number of alleles $(a)$, number of alleles with a frequency $<5 \%(a F)$, mean value of unbiased diversity $(u h)$, and number of private alleles $(P a)$. The number of unique genotypes was calculated for the whole dataset and for each morphotaxon independently. The overall power of the loci to discriminate between individuals was calculated with an accumulation curve using the poprr package (Kamvar et al. 2015) implemented in R 3.2.2 (R Core Team 2015) with the function genotype_curve.

\section{Clustering analyses}

Species delimitation was performed using two different clustering methods: a model-based Bayesian clustering analysis as implemented in STRUCTURE (Pritchard et al. 2000), and the Gaussian clustering (GC) as implemented in the R package prabclus (Hausdorf \& Hennig 2010).

STRUCTURE uses a model-based algorithm which assigns individuals to clusters with similar genetic patterns and assuming a Hardy-Weinberg equilibrium (Pritchard et al. 2000). The analyses were set up supporting dominant markers by adding a row of recessive alleles according to the manual (Pritchard et al. 2000). Missing data were coded as ' -9 '. Other options used were 'correlated allele frequencies' and 'no admixture', as it is regarded that these last parameters can detect subtle population structure (Falush et al. 2007; Porras-Hurtado et al. 2013). All individuals 
of the full dataset were considered a single population and morphotaxon assignment was not considered as a prior to avoid bias (Porras-Hurtado et al. 2013). An exploratory analysis was run to calculate the number of clusters $(\mathrm{K})$ that best fit the data. This consisted of 10 independent runs, $K=2$ to $K=18$ and 50,000 Markov chain Monte Carlo (MCMC) iterations with a burn-in of 50,000 . The best $\mathrm{K}$ was determined calculating the $\mathrm{Ln}(\mathrm{K})$ and Delta K values (Evanno et al. 2005) in STRUCTURE HARVESTER (Earl \& vonHoldt 2012). A more extensive analysis was done to improve cluster assignment performance using the selected $\mathrm{K}, 10$ independent runs, each of 250,000 MCMC iterations with 250,000 iterations of burn-in. A consensus Q matrix was obtained in CLUMPAK (Kopelman et al. 2015) using the greedy algorithm and plotted using STRUCTURE PLOT (Ramasamy et al. 2014).

Gaussian clustering algorithm constructs clusters according to the normal distribution that can best explain the differences between individuals (Carstens et al. 2013; Hausdorf \& Hennig 2010; Mrinalini et al. 2015; Sauer et al. 2013). The data matrix was transformed into pairwise distance matrices using the Jaccard index. As prabclust cannot deal with missing data, they were transformed into absences (' 0 '). The number of clusters was inferred with the function prabclus using the 'kruskal' nonmetric multidimensional scaling (NMDS), without 'noise component', with the number of clusters ranging from 2 to 18 , and 99 permutations. The number of dimensions was calculated using the stressvals function with dimensions ranging from 2 to 10 , selecting a value below $10 \%$ as suggested by the authors of the program (prabclus documentation).

Finally, the resulting assignments were compared, looking for clusters consistent with each morphotaxon and for agreement between both clustering methods. The proportion of individuals assigned to only one cluster was calculated and heat map-like bidimensional plots were created using the R package adegraphics to visually compare the number of individuals assigned to each cluster.

\section{RESULTS}

\section{SSRs statistics}

Marker analyses revealed that individuals had more than two alleles for most loci (Table 2), except for locus 515-35 which had up to two. Although the number of alleles per individual in each locus was up to 8 (i.e. loci 14 and 34), PIC values for each locus ranged from 0.09 to 0.41 (average of 0.22 ). The number of missing data in all alleles was relatively low $(<1 \%)$, except for loci 14 (6.6\%) and 34 (36.0\%). In spite of the missing data, we decided to include these loci in the analysis, as missing data occurred mainly in $\mathrm{Cl}$. floccosa, Cl. meyeri, and Cl. globulus, and the loci were informative for the remaining morphotaxa.

The number of alleles found among all 11 loci was 170 and the number of alleles per morphotaxon ranged from 31 to 101 (Table 3). The overall unbiased diversity value $(u h)$ was 0.068 , ranging from 0.029 to 0.118 . The proportion of alleles with a frequency $<5 \%(a F)$ ranged from $21.1 \%$ to $52.5 \%$. A total of 21 private alleles $(\mathrm{Pa})$ were detected, ranging from 0 to 4 per morphotaxon. A total of 600 different genotypes were detected. The majority of morphotaxa showed a large proportion of unique genotypes, except for Ch. moniliformis (only $34 \%$ unique) and the unattached form of Ch. curta (57\%; Table 3). The cumulative curve plot of loci versus number of genotypes showed that the markers had sufficient power to discriminate each individual as the curve plateaus (Fig. S2).

\section{Species delimitation by cluster analysis}

The results of the exploratory analysis in STRUCTURE revealed that $\mathrm{K}=12$ was the number of clusters that best fit the data [mean $\operatorname{Ln} \mathrm{P}(\mathrm{K})=-12,517.6]$ based on the $\Delta \mathrm{K}$ plot (Fig. S3). The number of individuals by cluster ranged from 16 to 133 . Most morphotaxa were recovered as independent clusters containing a large proportion of the pre-identified individuals (Figs 2, 3; Table S4). One hundred percent assignment of morphotaxa to clusters was found in Ch. baicalenesis (cluster $=3_{\text {strc }}$ ); the attached form of Ch. curta $\left(6_{\text {strc }}\right)$; Ch. moniliformis $\left(5_{\text {strc }}\right)$; and Cl. kursanovii $\left(2_{\text {strc }}\right)$. In addition, a high value of $76 \%$ occurred for $\mathrm{Cl}$. compacta $\left(1_{\text {strc }}\right)$. A good proportion of individuals of both varieties $\mathrm{Cl}$. meyeri var. meyeri and $\mathrm{Cl}$. meyeri var. gracilior $\left(66.67 \%\right.$ each) was assigned to the same cluster $\left(4_{\text {strc }}\right)$. For the two varieties of $\mathrm{Cl}$. floccosa, the assignment to independent clusters was not clear. Instead, they appeared in different clusters mixed with samples of $\mathrm{Cl}$. compacta and Gemmiphora compacta $\left(7_{\text {strc }}\right)$ and Cladophora pulvinata $\left(9_{\text {strc }}\right)$, respectively.

Table 2. Characteristics and number of alleles by locus for studied SSR loci. Groups according to Boedeker et al. (2018).

\begin{tabular}{|c|c|c|c|c|c|c|}
\hline Locus name & $\begin{array}{l}\text { SSR } \\
\text { motif }\end{array}$ & $\begin{array}{c}\text { Total number of } \\
\text { alleles }\end{array}$ & $\begin{array}{l}\text { Alleles per } \\
\text { individual }\end{array}$ & $\begin{array}{l}\text { Average number of } \\
\text { alleles }\end{array}$ & $\begin{array}{l}\text { Polymorphic information } \\
\text { content }\end{array}$ & $\begin{array}{l}\text { Cross- } \\
\text { amplification }\end{array}$ \\
\hline $5 a$ & TAC & 12 & 1 to 5 & 2.5 & 0.24 & All \\
\hline 14 & ATA & 27 & 1 to 8 & 2.6 & 0.14 & All \\
\hline 15 & AAT & 4 & 1 to 4 & 2.4 & 0.33 & Group A only \\
\hline 34 & TCA & 31 & 1 to 8 & 2.2 & 0.09 & All \\
\hline 46 & $\mathrm{TA}$ & 16 & 1 to 5 & 1.8 & 0.09 & All \\
\hline $50-15$ & TTA & 40 & 1 to 7 & 2.5 & 0.09 & All \\
\hline $515-35$ & ATT & 2 & 1 to 2 & 1.4 & 0.37 & Group A only \\
\hline $515-46$ & TTGT & 3 & 1 to 3 & 2.3 & 0.41 & Group A only \\
\hline
\end{tabular}


Table 3. Characteristics and genetic diversity of the SSRs in each morphotaxon. Total number of individuals $(\mathrm{N})$, number of alleles $(a)$, alleles with a frequency < $5 \%(a F)$, mean value of unbiased diversity $(u h)$, number of unique genotypes and the number of private alleles $(\mathrm{Pa})$ are shown. $\mathrm{Ch} .=$ Chaetomorpha, Cl. = Cladophora

\begin{tabular}{lrrrrrr}
\hline Morphotaxa & $\mathrm{N}$ & $a$ & aF & uh & Unique genotypes & $\mathrm{Pa}$ \\
\hline Chaetomorpha baicalensis & 30 & 39 & 6 & 0.029 & 25 & 1 \\
\hline Ch. curta attached & 41 & 50 & 12 & 0.049 & 39 & 0 \\
\hline Ch. curta unattached & 21 & 34 & 2 & 0.048 & 12 & 0 \\
\hline Ch. moniliformis & 122 & 38 & 16 & 0.012 & 41 & 0 \\
\hline Cladophora compacta & 127 & 101 & 53 & 0.084 & 126 & 4 \\
Cl. floccosa var. floccosa & 65 & 86 & 34 & 0.098 & 62 & 3 \\
Cl. floccosa var. irregularis & 65 & 73 & 19 & 0.118 & 65 & 2 \\
\hline Cl. globulus/Cl. Compacta & 31 & 72 & 18 & 0.105 & 31 & 2 \\
\hline Cl. globulus/Cl. pulvinata & 21 & 63 & 19 & 0.076 & 21 & 1 \\
Cl. kursanovii & 100 & 55 & 16 & 0.042 & 76 & 3 \\
\hline Cl. meyeri var. gracilior & 30 & 72 & 11 & 0.115 & 30 & 3 \\
\hline Cl. meyeri var. meyeri & 30 & 72 & 8 & 0.096 & 30 & 2 \\
\hline Cl. pulvinata & 20 & 60 & 0 & 0.072 & 20 & 0 \\
\hline Gemmiphora compacta & 20 & 42 & 0 & 0.040 & 20 & 0 \\
\hline Rhizoclonium sp. & 4 & 31 & 0 & 0.034 & 4 & 0 \\
\hline
\end{tabular}

Rhizoclonium sp. was assigned to cluster $6_{\text {strc }}$ which included the attached form of Ch. curta and some individuals of the unattached form. The samples of $\mathrm{Cl}$. globulus/Cl. compacta and $\mathrm{Cl}$. globulus/Cl. pulvinata were assigned mostly to cluster $12_{\text {strc }}$ with the inclusion of a few individuals of other morphotaxa (Fig. 3). The cluster $8_{\text {strc }}$ contained only a few individuals of various morphotaxa. The cluster assignment for each individual is shown in Table S5.

The Gaussian clustering was used with NMDS $=4$, which had an optimum imprecision of $8.18 \%$. Fourteen clusters were recovered. Although there was no clear distinction of each cluster in the $2 \mathrm{D}$ plot, this was a false impression because two other dimensions are not displayed (Fig. S4). The clusters contained from 14 to 112 individuals. The overall assignment was similar to STRUCTURE but slight differences were observed (Fig. 4). For example, Ch. moniliformis and $\mathrm{Cl}$. kursanovii, previously recognised in STRUCTURE as single clusters, were further divided ( $7_{\mathrm{GC}}$ and $9_{\mathrm{GC}}$ and $2 \mathrm{GC}_{\mathrm{GC}}$ and $3_{\mathrm{GC}}$, respectively), and the assignment of a few individuals also differed (Table S6).

\section{DISCUSSION}

Our results indicate that many morphologically distinguishable species are discrete genetic clusters. While traditional molecular markers based on ribosomal DNA sequences are not able to resolve species in the clade of Baikalian Cladophoraceae, population genetics using SSRs provided evidence to delimit these species. Species delimitation is fundamental in several biological disciplines but remains a difficult task due to the complexity of the speciation process and to uncertainty of which species concepts and criteria are most appropriate to distinguish between species (Carstens et al. 2013; Duminil \& Di Michele 2009; Leache \& Fujita 2010). Under the 'species as lineages framework' (De Queiroz 2007) the use of different data sources is crucial to correctly delimit species (Carstens et al. 2013).
Most loci had more than two alleles (Table 2) supporting the occurrence of polyploidy in this group and complicating population genetic analyses (Díaz-Martínez et al. 2020). It was not possible to determine the ploidy level of each individual (including the haploid stages) as no correlation was observed in the number of alleles between loci. Two loci had up to eight alleles suggesting up to octoploidy (loci 14 and 34; Table 2). An analysis of chromosome numbers (Hinson \& Kapraun 1991) or total DNA content (Kapraun 2007) may elucidate ploidy level changes. However, this was not possible with our samples and will need further work using new collections.

The PIC values showed that many of the SSRs used have a relatively high diversity (the maximum value expected for dominant markers is 0.5; Roldan-Ruiz et al. 2000) and are therefore adequate for the analyses. Noteworthy, loci 14 and 34 were the SSRs that showed the highest number of alleles and also had the largest proportion of missing data. However, this appears to have had no significant effects on the genetic clustering methods (see below). We speculate that these results could be related to mutations in flanking regions.

The proportion of unique genotypes is high in most morphotaxa. However, this is not the case for Ch. moniliformis, where only $34 \%$ of samples had unique multi-locus genotypes and had a low unbiased diversity value $(u h=0.012)$, even though this species had one of the largest sample sizes. This suggests that clonal reproduction, by either fragmentation or zoospores (as observed in freshwater species Cl. glomerata; van den Hoek et al. 1995; Zulkifly et al. 2013) may be prevalent in this species, although the actual mechanism is still unknown. This finding contrasts with $\mathrm{Cl}$. compacta and $\mathrm{Cl}$. kursanovii ( $u h=0.084$ and $u h=0.042$, respectively), morphotaxa also with large distribution ranges which exhibit a much higher proportion of unique genotypes (99\% and 76\%, respectively). To our knowledge, the life cycle of these species is still unknown (Izhboldina 2007), but the different diversity values may indicate other reproductive strategies such as sexual reproduction. Further analyses will be performed to explore the genetic diversity and reproductive strategies of these species in the lake.

STRUCTURE has been used widely in studies where polyploidy is present and the alleles are coded as allelic phenotypes. This may be attributed to its extensive use among population geneticists and the relatively easy and explicit input of binary data matrices obtained from dominant markers (Meudt et al. 2009). However, it is reported that STRUCTURE can fail in obtaining the 'correct' $\mathrm{K}$ (clusters) if deviations from HardyWeinberg equilibrium are present (Hausdorf \& Hennig 2010; Huelsenbeck et al. 2011). For this reason, the use of complementary and independent methods is recommended (Hausdorf \& Hennig 2010; Kamvar et al. 2014). Gaussian clustering uses mixtures of normal allele frequency distributions and therefore is regarded as a good alternative to model-based methods for dominant data (Hausdorf \& Hennig 2010; Sauer \& Hausdorf 2012; Sauer et al. 2013).

Other potential bias to species delimitation by genetic clustering might be the decoupling of the life cycles (dominance of sporophyte or gametophyte in populations) (Krueger-Hadfield et al. 2016) and the isolation of asexual lineages from the original populations during the transition 


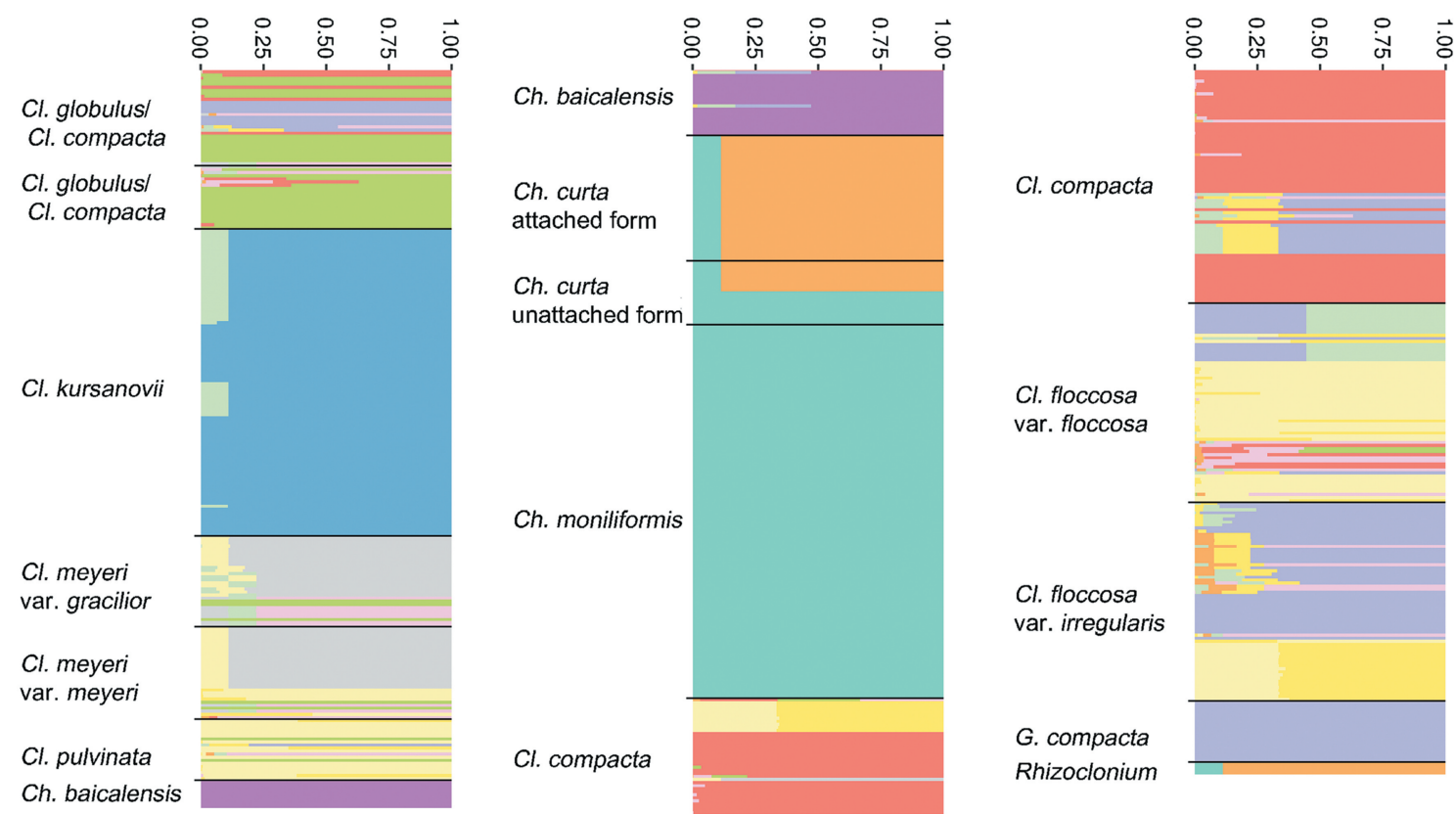

Fig. 2. Assignment of individuals by STRUCTURE $(K=12)$. Bar plot indicating the probability of assignment of each individual to a given cluster (by colour).

from sexuality to asexuality (Dudgeon et al. 2017). This is a possible scenario for those morphotaxa that were divided into two or more genetic clusters (e.g. Ch. moniliformis and Cl. kursanovii; Fig. 3). However, this effect appears to be negligible because of the low genetic differentiation observed in most of these clusters. Finally, the combination of samples of unknown ploidy level may have influenced the species delimitation, particularly for morphotaxa samples that could not be assigned properly to any genetic cluster or for morphotaxa assigned to more than one cluster (e.g. both varieties of $\mathrm{Cl}$. floccosa). If sexual reproduction and alternation of haploid and diploid phases occur, the genetic diversity could be underestimated (Krueger-Hadfield \& Hoban 2016), and the genetic structure might not be well determined (Wang et al. 2008). Future research is needed to determine the life cycle of the Baikalian species and their population structure.

The two cluster analyses (STRUCTURE and GC) produced comparable results, although GC recovered two more clusters than STRUCTURE, and other subtle differences in the assignment of individuals were observed. These genetic clusters likely correspond to reproductively isolated lineages as the assignment did not lump individuals based on locality or geographic regions, but mostly by morphotaxa. The cluster delimitation supports many of the morphotaxa identified in this study, such as Ch. baicalenesis, $\mathrm{Ch}$. curta (attached form), Ch. moniliformis, Cl. compacta, and Cl. kursanovii. Some individuals of the unattached form of Chaetomorpha curta and Ch. moniliformis were recovered in the same cluster in both methods, supporting their conspecificity. The two types of thalli appear similar in shape and size, with the only difference being the attached or unattached habit. However, another group of samples of unattached Ch. curta was assigned to the same cluster as the attached form, which may indicate that the unattached morphology is influenced by environment and can arise in different species. In spite of their morphological differences, the attached form of Ch. curta and Rhizoclonium sp. were placed in the same cluster by STRUCTURE $\left(6_{\text {strc }}\right)$ supporting the ITS phylogeny obtained by Boedeker et al. (2018). The GC placed the Rhizoclonium samples in a Ch. moniliformis cluster $\left(8_{\mathrm{GC}}\right)$ indicating slight genetic differences from Ch. curta. A more detailed analysis is required to confirm if this is evidence of hybridisation or an artefact of the data. For Cl. meyeri, the analysis suggests no genetic distinction between either variety, similarly to the ITS phylogeny (Boedeker et al. 2018). Our results also show that both $\mathrm{Cl}$. globulus/Cl. compacta and $\mathrm{Cl}$. globulus/Cl. pulvinata may actually belong to the same species. The remaining morphotaxa, namely $\mathrm{Cl}$. foccosa var. irregularis, Cl. floccosa var. floccosa, Cl. pulvinata, and Gemmiphora compacta, have unclear assignments with both methods (clusters $7-11_{\text {strc }}$ and $4-12_{\mathrm{GC}}$ ), and a re-examination of their morphological characteristics is needed. Furthermore, our results indicate that a reassessment of the taxonomy and nomenclature of the Cladophoraceae species of Lake Baikal is required. Unfortunately, this requires a more intensive taxonomic review for not only these species but for the entire order, as shown by previous phylogenetic analyses of Cladophoraceae (Boedeker et al. 2016, 2018).

Polyploidy is likely to have occurred in this group, making it interesting for the study of speciation and evolution. Polyploidy is regarded as a form of instant speciation as the offspring becomes reproductively incompatible with their parents (Albert \& Schluter 2005; Schluter 2001). This may also explain the morphological variation in the group, because polyploidy is also often related to morphological changes (Comai 2005; Herben et al. 2017). The formation of polyploids via genome doubling (autopolyploids) or hybridisation (allopolyploids) could have led to the diversification of Baikalian Cladophoraceae, as it has been reported that 
3

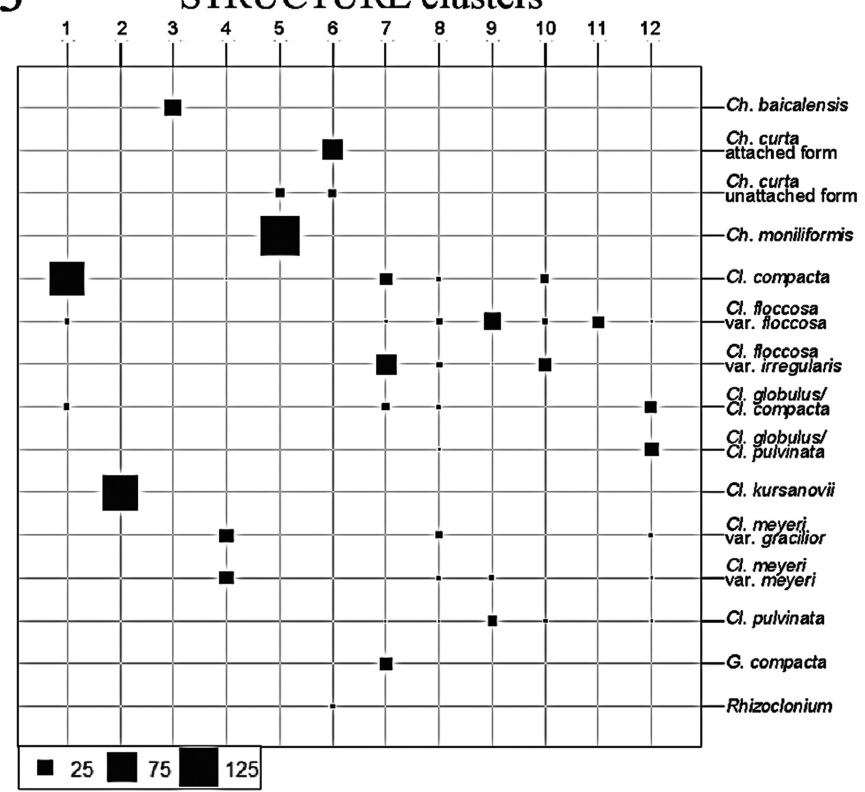

4

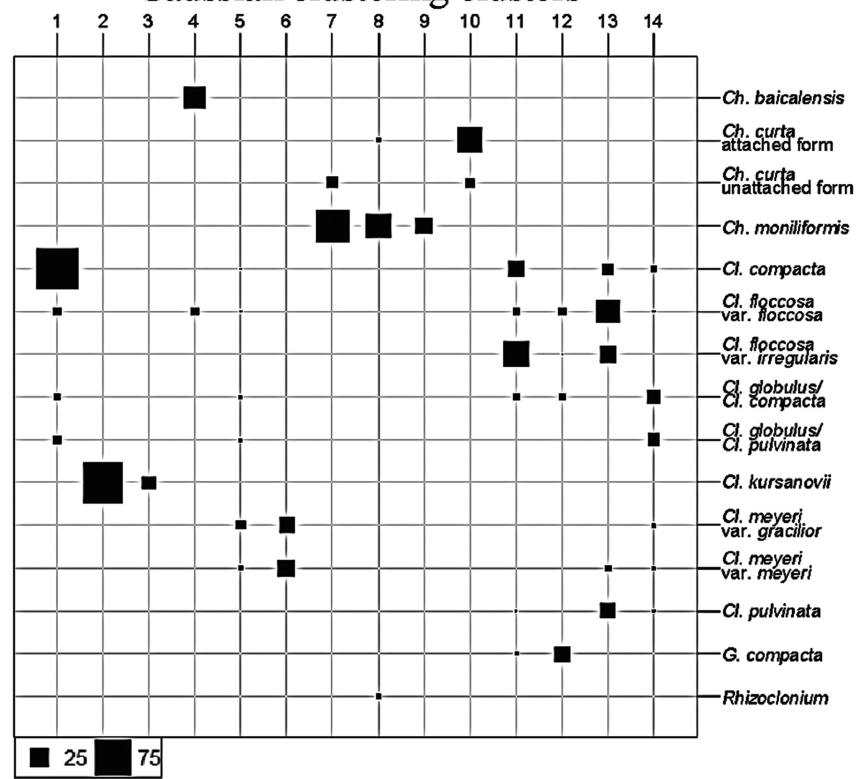

Figs 3-4. Bidimensional plots showing the number of individuals of each morphotaxa (rows) assigned to a given cluster (columns). For total number of individuals assigned to each cluster see Tables S4 and S6.

Fig. 3. Bidimensional plot from STRUCTURE data with 12 clusters recovered. Fig. 4. Bidimensional plot from Gaussian clustering data with 14 clustersre covered.

polyploidisation favours the establishment of species in new environments (Soltis et al. 2010; Te Beest et al. 2012). The role of polyploidy was not solved and studies including other sources of data (i.e. DNA content or chromosome counting) will be necessary to reveal ploidy changes and their influence in speciation and adaption in these species.

Lake Baikal has undergone several geological (Logatchev 1993; Mats 1993) and climatic changes (Sherstyankin \& Kuimova 2006). The transition of the region into a subarctic climate (c. 2.4 mya) coincides with a major change in the diversification of many species in the lake (Karanovic \& Sitnikova 2017; Schön \& Martens 2012; Sherbakov 1999; Stelbrink et al. 2015; Yokoyama \& Goto 2005). An accurate timing of the diversification of these algal morphotaxa would indicate whether or not this diversification correlates with these environmental changes.

The Baikalian Cladophorales species flock shows a complex evolutionary history that remains to be fully understood. One of the most intriguing questions about this group is if the species have diversified in sympatry. A finer analysis of population genetics may help to understand the population structure, the genetic diversity within species, and provide further evidence of speciation in sympatry such as gene flow between populations and lack of isolation by distance (Coyne \& Orr 2004).

The species delimitation performed on the Baikalian Cladophoraceae allowed us to delimit many of the species as genetic clusters that support reproductive isolation of lineages. This is further supported by the cluster analyses which did not lump individuals based on locality or geographic regions, but mostly by morphotaxa. It was possible to delimit five out of 15 morphotaxa with $100 \%$ confidence (Figs 3, 4; Table S5); two morphotaxa pairs seem to be conspecific; and two other morphotaxa are growth forms of other species. The remaining morphotaxa could not be fully resolved and need deeper review and additional data. The endemic Cladophoraceae species of Lake Baikal are a recently discovered group with many properties of a species flock (Boedeker et al. 2018) that may have evolved in sympatry or via polyploidisation. Therefore, it might represent one of the first examples of sympatric speciation in algae.

\section{ACKNOWLEDGEMENTS}

We thank the Royal Society of New Zealand (Marsden Fund FastStart grant to CB) for the funds provided for this research. SDM thanks Victoria University of Wellington for a Doctoral Scholarship. O. A. Timoshkin, A. Kupchinsky and the crews of the research vessels Titov, Papanin and Koptyug (Limnological Institute of the Russian Academy of Sciences, Irkutsk) as well as S. Ihnken are thanked for their assistance with fieldwork. Finally, we thank F. Leliaert, the editors, and an anonymous reviewer for valuable comments and suggestions on the manuscript.

\section{FUNDING}

We thank the Royal Society of New Zealand (Marsden Fund FastStart) for the funds provided for this research. SDM thanks Victoria University of Wellington for a Doctoral Scholarship.

\section{ORCID}

Sergio Díaz Martínez (D) http://orcid.org/0000-0002-9164-5976 Christian Boedeker (D) http://orcid.org/0000-0001-5230-4581 Giuseppe C. Zuccarello (D) http://orcid.org/0000-0003-0028-7227

\section{REFERENCES}

Abuzayed M., El-Dabba N., Frary A. \& Doganlar S. 2017. GDdom: an online tool for calculation of dominant marker gene diversity. Biochemical Genetics 55: 155-157. DOI: 10.1007/s10528-016-9779-0. 
Albert A.Y.K. \& Schluter D. 2005. Selection and the origin of species. Current Biology 15: R283-288. DOI: 10.1016/j.cub.2005.04.015.

Andreakis N., Kooistra W.H.C.F. \& Procaccini G. 2009. High genetic diversity and connectivity in the polyploid invasive seaweed Asparagopsis taxiformis (Bonnemaisoniales) in the Mediterranean, explored with microsatellite alleles and multilocus genotypes. Molecular Ecology 18: 212-226. DOI: 10.1111/j.1365-294X.2008.0 4022.x.

Barluenga M., Stölting K.N., Salzburger W., Muschick M. \& Meyer A. 2006. Sympatric speciation in Nicaraguan crater lake cichlid fish. Nature 439: 719-723. DOI: 10.1038/nature04325.

Boedeker C., Leliaert F., Timoshkin O.A., Vishnakov V., Díaz-Martínez S. \& Zuccarello G.C. 2018. The endemic Cladophorales (Ulvophyceae) of ancient Lake Baikal represent a monophyletic group of very closely related but morphologically diverse species. Journal of Phycology 54: 616-629. DOI: 10.1111/jpy.12773.

Boedeker C., Leliaert F. \& Zuccarello G.C. 2016. Molecular phylogeny of the Cladophoraceae (Cladophorales, Ulvophyceae), with the resurrection of Acrocladus Nägeli and Willeella Børgesen, and the description of Lurbica gen. nov. and Pseudorhizoclonium gen. nov. Journal of Phycology 52: 905-928. DOI: 10.1111/jpy.12457.

Bruvo R., Michiels N.K., D’Souza T.G. \& Schulenburg H. 2004. A simple method for the calculation of microsatellite genotype distances irrespective of ploidy level. Molecular Ecology 13: 2101-2106. DOI: 10.1111/j.1365-294X.2004.02209.x.

Carstens B.C., Pelletier T.A., Reid N.M. \& Satler J.D. 2013. How to fail at species delimitation. Molecular Ecology 22: 4369-4383. DOI: 10.1111/ mec.12413.

Cidade F.W., Vigna B.B., de Souza F.H., Valls J.F.M., Dall'Agnol M., Zucchi M.I., de Souza-chies T.T. \& Souza A.P. 2013. Genetic variation in polyploid forage grass: assessing the molecular genetic variability in the Paspalum genus. BMC Genetics 14: 50. DOI: 10.1186/1471-2156-14-50.

Comai L. 2005. The advantages and disadvantages of being polyploid. Nature Reviews Genetics 6: 836-846. DOI: 10.1038/nrg1711.

Coyne J.A. \& Orr H.A. 2004. Speciation. Sinauer Associates, Sunderland, Massachusetts, USA. 545 pp.

Cristescu M.E., Adamowicz S.J., Vaillant J.J. \& Haffner D.G. 2010. Ancient lakes revisited: from the ecology to the genetics of speciation. Molecular Ecology 19: 4837-4851. DOI: 10.1111/j.1365294X.2010.04832.x.

De Queiroz K. 2007. Species concepts and species delimitation. Systematic Biology 56: 879-886. DOI: 10.1080/10635150701701083.

Defaveri J., Viitaniemi H., Leder E. \& Merilä J. 2013. Characterizing genic and nongenic molecular markers: comparison of microsatellites and SNPs. Molecular Ecology Resources 13: 377-392. DOI: 10.1111/ 1755-0998.12071.

Díaz-Martínez S., Boedeker C. \& Zuccarello G.C. 2020. Microsatellite design for species delimitation and insights into ploidy for the Lake Baikal Cladophoraceae species flock. Phycologia. (in press).

Díaz-Martínez S., Zuccarello G.C., Chávez G.A.S., Pedroche F.F. \& AvilaOrtiz A.G. 2016. Species of Padina (Dictyotales, Phaeophyceae) in tropical Mexican waters based on molecular-assisted taxonomy. Phycologia 55: 673-687. DOI: 10.2216/16-15.1.

Dudgeon S., Kübler J.E., West J.A., Kamiya M. \& Krueger-Hadfield S.A. 2017. Asexuality and the cryptic species problem. Perspectives in Phycology 4: 47-59. DOI: 10.1127/pip/2017/0070.

Duminil J. \& Di Michele M. 2009. Plant species delimitation: a comparison of morphological and molecular markers. Plant Biosystems 143: 528-542. DOI: 10.1080/11263500902722964.

Earl D.A. \& vonHoldt B.M. 2012. STRUCTURE HARVESTER: a website and program for visualizing STRUCTURE output and implementing the Evanno method. Conservation Genetics Resources 4: 359-361. DOI: 10.1007/s12686-011-9548-7.

Edwards D.L. \& Knowles L.L. 2014. Species detection and individual assignment in species delimitation: can integrative data increase efficacy? Proceedings of the Royal Society B: Biological Sciences 281: 20132765. DOI: 10.1098/rspb.2013.2765.

Evanno G., Regnaut S. \& Goudet J. 2005. Detecting the number of clusters of individuals using the software STRUCTURE: a simulation study. Molecular Ecology 14: 2611-2620. DOI: 10.1111/j.1365294X.2005.02553.x.

Falush D., Stephens M. \& Pritchard J.K. 2007. Inference of population structure using multilocus genotype data: dominant markers and null alleles. Molecular Ecology Notes 7: 574-578. DOI: 10.1111/j.14718286.2007.01758.x.

Fitzpatrick B.M., Fordyce J.A. \& Gavrilets S. 2009. Pattern, process and geographic modes of speciation. Journal of Evolutionary Biology 22: 2342-2347. DOI: 10.1111/j.1420-9101.2009.01833.x.

Fujisawa T. \& Barraclough T.G. 2013. Delimiting species using single-locus data and the generalized mixed yule coalescent approach: a revised method and evaluation on simulated data sets. Systematic Biology 62: 707-724. DOI: 10.1093/sysbio/syt033.

García-Verdugo C., Calleja J.A., Vargas P., Silva L., Moreira O. \& Pulido F. 2013. Polyploidy and microsatellite variation in the relict tree Prunus lusitanica L.: how effective are refugia in preserving genotypic diversity of clonal taxa? Molecular Ecology 22: 1546-1557. DOI: $10.1111 / \mathrm{mec} .12194$.

Goff L. \& Moon D. 1993. PCR amplification of nuclear and plastid genes from algal herbarium specimens and algal spores. Journal of Phycology 29: 381-384. DOI: 10.1111/j.0022-3646.1993.00381.x.

Hausdorf B. \& Hennig C. 2010. Species delimitation using dominant and codominant multilocus markers. Systematic Biology 59: 491-503. DOI: 10.1093/sysbio/syq039.

Herben T., Suda J. \& Klimešová J. 2017. Polyploid species rely on vegetative reproduction more than diploids: a re-examination of the old hypothesis. Annals of Botany 120: 341-349. DOI: 10.1093/aob/ mcx009.

Herder F., Pfaender J. \& Schliewen U.K. 2008. Adaptive sympatric speciation of polychromatic "roundfin" sailfin silverside fish in Lake Matano (Sulawesi). Evolution 62: 2178-2195. DOI: 10.1111/j.15585646.2008.00447.x.

Hinson T.K. \& Kapraun D.F. 1991. Karyology and nuclear DNA quantification of four species of Chaetomorpha (Cladophoraceae, Chlorophyta) from the western Atlantic. Helgoland Marine Research 45: 273-385. DOI: 10.1007/bf02365520.

Huelsenbeck J.P., Andolfatto P. \& Huelsenbeck E.T. 2011. Structurama: Bayesian inference of population structure. Evolutionary Bioinformatics 2011: 55-59. DOI: 10.4137/EBO.S6761.

Izhboldina L. 2007. Guide and key to benthonic and periphyton algae of Lake Baikal (meio- and macrophytes) with short notes of their ecology. Nauka-Tsentr, Novosibirsk, RU. 248 pp.

Jombart T., Devillard S. \& Balloux F. 2010. Discriminant analysis of principal components: a new method for the analysis of genetically structured populations. BMC Genetics 11: 94. DOI: 10.1186/14712156-11-94.

Kamvar Z.N., Brooks J.C. \& Grünwald N.J. 2015. Novel R tools for analysis of genome-wide population genetic data with emphasis on clonality. Frontiers in Genetics 6: 1-10. DOI: 10.3389/ fgene.2015.00208.

Kamvar Z.N., Tabima J.F. \& Grünwald N.J. 2014. Poppr: an R package for genetic analysis of populations with clonal, partially clonal, and/or sexual reproduction. PeerJ 2: e281. DOI: 10.7717/peerj.281.

Kapraun D.F. 2007. Nuclear DNA content estimates in green algal lineages: Chlorophyta and Streptophyta. Annals of Botany 99: 677-701. DOI: 10.1093/aob/mcl294.

Karanovic I. \& Sitnikova T.Y. 2017. Phylogenetic position and age of Lake Baikal candonids (Crustacea, Ostracoda) inferred from multigene sequence analyzes and molecular dating. Ecology and Evolution 7: 7091-7103. DOI: 10.1002/ece3.3159.

Keller I., Wagner C.E., Greuter L., Mwaiko S., Selz O.M., Sivasundar A., Wittwer S. \& Seehausen O. 2013. Population genomic signatures of divergent adaptation, gene flow and hybrid speciation in the rapid radiation of Lake Victoria cichlid fishes. Molecular Ecology 22: 2848-2863. DOI: 10.1111/mec.12083.

Kopelman N.M., Mayzel J., Jakobsson M., Rosenberg N.A. \& Mayrose I. 2015. CLUMPAK: a program for identifying clustering modes and packaging population structure inferences across K. Molecular Ecology Resources 15: 1179-1191. DOI: 10.1111/1755-0998.12387. 
Krueger-Hadfield S.A. \& Hoban S.M. 2016. The importance of effective sampling for exploring the population dynamics of haploid-diploid seaweeds. Journal of Phycology 52: 1-9. DOI: 10.1111/jpy.12366.

Krueger-Hadfield S.A., Kollars N.M., Byers J.E., Greig T.W., Hammann M., Murray D.C., Murren C.J., Strand A.E., Terada R., Weinberger F. et al. 2016. Invasion of novel habitats uncouples haplo-diplontic life cycles. Molecular Ecology 25: 3801-3816. DOI: 10.1111/mec.13718.

Leache A.D. \& Fujita M.K. 2010. Bayesian species delimitation in West African forest geckos (Hemidactylus fasciatus). Proceedings of the Royal Society B: Biological Sciences 277: 3071-3077. DOI: 10.1098/ rspb.2010.0662.

Leliaert F., Verbruggen H., Vanormelingen P., Steen F., López-Bautista J. M., Zuccarello G.C. \& De Clerk O. 2014. DNA-based species delimitation in algae. European Journal of Phycology 49: 179-196. DOI: 10.1080/09670262.2014.904524.

Logatchev N. 1993. History and geodynamics of the Lake Baikal Rift in the context of the Eastern Siberia rift system: a review. Bulletin, Centre de Recherche, Exploration et Production, Elf Aquitaine 17: 353-370.

López-Vinyallonga S., Soriano I., Susanna A., Montserra J.M., Roquet C. \& Garcia-Jacas N. 2015. The polyploid series of the Achillea millefolium aggregate in the Iberian Peninsula investigated using microsatellites. PLOS One 10: 1-19. DOI: 10.1371/journal. pone.0129861.

Mallet J. 1995. A species definition for the modern synthesis. Trends in Ecology \& Evolution 10: 294-299. DOI: 10.1016/0169-5347(95)90031-4.

Mats V. 1993. The structure and development of the Baikal rift depression. Earth-Science Reviews 34: 81-118. DOI: 10.1016/00128252(93)90028-6.

Mayr E. 2000. The biological species concept. In: Species concepts and phylogenetic theory (Ed. by Q. Wheeler \& R. Meier), pp. 17-29. Columbia University Press, New York, NY, USA. 256

Meudt H.M., Lockhart P.J. \& Bryant D. 2009. Species delimitation and phylogeny of a New Zealand plant species radiation. BMC Evolutionary Biology 9: 1-17. DOI: 10.1186/1471-2148-9-111.

Mrinalini T.R.S., Creer S., Lallias D., Dawnay L., Stuart B.L. \& Malhotra A. 2015. Convergence of multiple markers and analysis methods defines the genetic distinctiveness of cryptic pitvipers. Molecular Phylogenetics and Evolution 92: 266-279. DOI: 10.1016/j. ympev.2015.06.001.

Muangmai N., West J.A. \& Zuccarello G.C. 2014. Evolution of four Southern Hemisphere Bostrychia (Rhodomelaceae, Rhodophyta) species: phylogeny, species delimitation and divergence times. Phycologia 53: 593-601. DOI: 10.2216/14-044.1.

Nielsen R., Paul J.S., Albrechtsen A. \& Song Y.S. 2011. Genotype and SNP calling from next-generation sequencing data. Nature Reviews, Genetics 12: 443-451. DOI: 10.1038/nrg2986.

Obbard D.J., Harris S.A. \& Pannell J.R. 2006. Simple allelic-phenotype diversity and differentiation statistics for allopolyploids. Heredity 97: 296-303. DOI: 10.1038/sj.hdy.6800862.

Peakall R. \& Smouse P.E. 2012. GenAlEx 6.5: genetic analysis in Excel. Population genetic software for teaching and research - an update. Bioinformatics 28: 2537-2539. DOI: 10.1093/bioinformatics/bts460.

Pfeiffer T., Roschanski A.M., Pannell J.R., Korbecka G. \& Schnittler M. 2011. Characterization of microsatellite loci and reliable genotyping in a polyploid plant, Mercurialis perennis (Euphorbiaceae). Journal of Heredity 102: 479-488. DOI: 10.1093/jhered/esr024.

Porras-Hurtado L., Ruiz Y., Santos C., Phillips C., Carracedo Á. \& Lareu M.V. 2013. An overview of STRUCTURE: applications, parameter settings, and supporting software. Frontiers in Genetics 4: 1-13. DOI: $10.3389 /$ fgene.2013.00098.

Pritchard J.K., Stephens M. \& Donnelly P. 2000. Inference of population structure using multilocus genotype data. Genetics 155: 945-959. DOI: 10.1111/j.1471-8286.2007.01758.x.

Puillandre N., Lambert A., Brouillet S. \& Achaz G. 2012. ABGD, automatic barcode gap discovery for primary species delimitation. Molecular Ecology 21: 1864-1877. DOI: 10.1111/j.1365-294X.2011.05239.x.

R Core Team. 2015. R: A language and environment for statistical computing. R Foundation for Statistical Computing, Vienna, Austria. https://www.R-project.org.
Ramasamy R.K., Ramasamy S., Bindroo B.B. \& Naik V.G. 2014. STRUCTURE PLOT: A program for drawing elegant STRUCTURE bar plots in user friendly interface. SpringerPlus 3: 1-3. DOI: 10.1186/ 2193-1801-3-431.

Roldan-Ruiz I., Dendauw J., Van Bockstaele E., Depicker A. \& De Loose M. 2000. AFLP markers reveal high polymorphic rates in ryegrass (Lolium spp.). Molecular Breeding 6: 125-134. DOI: 10.1023/A:1009680614564.

Salzburger W. \& Meyer A. 2004. The species flocks of East African cichlid fishes: recent advances in molecular phylogenetics and population genetics. Die Naturwissenschaften 91: 277-290. DOI: 10.1007/ s00114-004-0528-6.

Samah S., De Teodoro Pardo C.V., Serrato Cruz M.A. \& ValadezMoctezuma E. 2016. Genetic diversity, genotype discrimination, and population structure of Mexican Opuntia sp., determined by SSR markers. Plant Molecuar Biology Reporter 34: 146-159. DOI: 10.1007/s11105-015-0908-4.

Sampson J.F. \& Byrne M. 2012. Genetic diversity and multiple origins of polyploid Atriplex nummularia Lindl. (Chenopodiaceae). Biological Journal of the Linnean Society 105: 218-230. DOI: 10.1111/j.10958312.2011.01787.x.

Sauer J. \& Hausdorf B. 2012. A comparison of DNA-based methods for delimiting species in a Cretan land snail radiation reveals shortcomings of exclusively molecular taxonomy. Cladistics 28: 300-316. DOI: 10.1111/j.1096-0031.2011.00382.x.

Sauer J., Oldeland J. \& Hausdorf B. 2013. Continuing fragmentation of a widespread species by geographical barriers as initial step in a land snail radiation on Crete. PLOS One 8: e62569. DOI: 10.1371/journal. pone.0062569.

Schluter D. 2001. Ecology and the origin of species. Trends in Ecology \& Evolution 16: 372-380. DOI: 10.1016/S0169-5347(01)02198-X.

Schoebel C.N., Brodbeck S., Buehler D., Cornejo C., Gajurel J., Hartikainen H., Keller D., Leys M., Ríčanová Š., Segelbacher G. et al. 2013. Lessons learned from microsatellite development for nonmodel organisms using 454 pyrosequencing. Journal of Evolutionary Biology 26: 600-611. DOI: 10.1111/jeb.12077.

Schön I. \& Martens K. 2012. Molecular analyses of ostracod flocks from Lake Baikal and Lake Tanganyika. Hydrobiologia 682: 91-110. DOI: 10.1007/s10750-011-0935-6.

Seehausen O. 2006. African cichlid fish: a model system in adaptive radiation research. Proceedings of the Royal Society B: Biological Sciences 273: 1987-1998. DOI: 10.1098/rspb.2006.3539.

Selkoe K.A. \& Toonen R.J. 2006. Microsatellites for ecologists: a practical guide to using and evaluating microsatellite markers. Ecology Letters 9: 615-629. DOI: 10.1111/j.1461-0248.2006.00889.x.

Shaffer H.B. \& Thomson R.C. 2007. Delimiting species in recent radiations. Systematic Biology 56: 896-906. DOI: 10.1080/ 10635150701772563.

Sherbakov D.Y. 1999. Molecular phylogenetic studies on the origin of biodiversity in Lake Baikal. Trends in Ecology \& Evolution 14: 92-95. DOI: 10.1016/S0169-5347(98)01543-2.

Sherstyankin P.P. \& Kuimova L.N. 2006. Hydrophysical processes in Lake Baikal in its transition from subtropical to modern climates. Hydrobiologia 568: 253-257. DOI: 10.1007/s10750-006-0306-x.

Škaloud P., Rindi F., Boedeker C. \& Leliaert F. 2018. Freshwater flora of Central Europe, Vol 13: Chlorophyta: Ulvophyceae. Springer, Berlin, Heidelberg, Germany. 289 pp. DOI: 10.1007/978-3-662-55495-1.

Soltis D.E., Buggs R., Doyle J. \& Soltis P.S. 2010. What we still don't know about polyploidy. Taxon 59: 1387-1403. DOI: 10.1002/tax.595006.

Stelbrink B., Shirokaya A.A., Clewing C., Sitnikova T.Y., Prozorova L.A. \& Albrecht C. 2015. Conquest of the deep, old and cold: an exceptional limpet radiation in Lake Baikal. Biology Letters 11: 20150321. DOI: $10.1098 /$ rsbl.2015.0321.

Sukumaran J. \& Knowles L.L. 2017. Multispecies coalescent delimits structure, not species. Proceedings of the National Academy of Sciences of the United States of America 114: 1607-1612. DOI: 10.1073/pnas.1607921114.

Te Beest M., Le Roux J.J., Richardson D.M., Brysting A.K., Suda J., Kubešová M. \& Pyšek P. 2012. The more the better? The role of polyploidy in facilitating plant invasions. Annals of Botany 109: 19-45. DOI: $10.1093 / \mathrm{aob} / \mathrm{mcr} 277$. 
van den Hoek C., Mann D.G. \& Jahns H.M. 1995. Algae: an introduction to phycology. Cambridge University Press, Cambridge, UK. 623 pp.

Volkova E.A., Bondarenko N.A. \& Timoshkin O.A. 2018. Morphotaxonomy, distribution and abundance of Spirogyra (Zygnematophyceae, Charophyta) in Lake Baikal, East Siberia. Phycologia 57: 298-308. DOI: 10.2216/17-69.1.

Wang X., Zhao F., Hu Z., Critchley A.T., Morrell S.L. \& Duan D. 2008. Inter-simple sequence repeat (ISSR) analysis of genetic variation of Chondrus crispus populations from North Atlantic. Aquatic Botany 88: 154-159. DOI: 10.1016/j.aquabot.2007.10.001.

Wiens J.J. 2007. Species delimitation: new approaches for discovering diversity. Systematic Biology 56: 875-878. DOI: 10.1080/1063515 0701748506.
Wilke T., Väinölä R. \& Riedl F. Eds. 2008. Patterns and processes of speciation in ancient lakes. Hydrobiologia 615: 235. DOI: 10.1007/978-1-4020-9582-5. Yokoyama R. \& Goto A. 2005. Evolutionary history of freshwater sculpins, genus Cottus (Teleostei; Cottidae) and related taxa, as inferred from mitochondrial DNA phylogeny. Molecular Phylogenetics \& Evolution 36: 654-668. DOI: 10.1016/j.ympev.2005.06.004.

Zhang J., Kapli P., Pavlidis P. \& Stamatakis A. 2013. A general species delimitation method with applications to phylogenetic placements. Bioinformatics 29: 2869-2876. DOI: 10.1093/bioinformatics/btt499.

Zulkifly S., Graham J., Young E., Mayer R., Piotrowski M., Smith I. \& Graham L. 2013. The genus Cladophora Kützing (Ulvophyceae) as a globally distributed ecological engineer. Journal of Phycology 49: 1-17. DOI: 10.1111/jpy.12025. 